\title{
Analisis Potensi Wisata Berbasis Budaya dengan Pendekatan Community Based Tourism (CBT) di Desa Budaya Lung Anai, Kutai Kartanegara
}

\author{
Eman Sukmana ${ }^{1 *}$, Himawan Brahmantyo ${ }^{2}$, dan Tauhid Hira ${ }^{3}$ \\ Iemansukmana@polnes.ac.id; ${ }^{2}$ himawanbrahmantyo@stptrisakti.ac.id; ${ }^{3}$ tohhipolnes@gmail.com. \\ 1,3 Jurusan Pariwisata Politeknik Negeri Samarinda, Kota Samarinda, 75136, Indonesia \\ ${ }^{2}$ STP Trisakti, Bintaro, Kota Jakarta Selatan, 12330, Indonesia \\ ${ }^{1,3}$ Jl. DR. Ciptomangunkusumo, Kampus Gunung Lipan, Samarinda, Kalimantan Timur, Indonesia $75131 \mid$ Hot line: \\ PABX (+62541) 260588, FAX: (+62541) 260355 \\ ${ }^{2}$ Jl. IKPN Bintaro No 1, Pesanggrahan, Tanah Kusir, Daerah Khusus Ibukota Jakarta 12330 \\ * corresponding author
}

ARTICLE INFO (8 pt)

Article history:

Received

Revised

Accepted

Keywords: Cultural Village, Lung Anai, Tourism, Community-Based Tourism.

Kata kunci: Desa Budaya, Lung Anai, Pariwisata, Pariwisata Berbasis Masyarakat..
ABSTRACT (10PT)

In 2005 Lung Anai Village was inaugurated by the Government of Kutai Kartanegara Regency as a cultural village based on the survey results and the cultural uniqueness of the Dayak Kenyah Tribe. Thus, on July 25, 2007 Lung Anai was established as a definitive village that stood alone by the Decree of the Kukar Regent No. 180,188 / HK-794/2007. The stipulation is expected to be able to boost economic development for the welfare of the community and increase the Kukar Regional Original Income (PAD) as well as to preserve the culture of Dayak Kenyah Lepoq Jalan tribes in Lung Anai Village. But in reality the goal has not been realized properly, until this year Lung Anai has not become a leading destination in Kukar. If observed in the literature, there is still a considerable gap with other cultural / tourist villages that have developed even independent in East Kalimantan. This study aims to comprehensively analyze the tourism potentials of Lung Anai Village based on culture by conducting a community-based tourism (CBT) approach or community-based tourism. In addition, this research is also expected to be able to provide theoretical and technical recommendations for the Regional Government of Kutai Kartanegara District and stakeholders who have a common interest in developing the Lung Anai Cultural Village.

\section{ABSTRAK}

Pada tahun 2005 Kampung Lung Anai diresmikan oleh Pemerintah Kabupaten Kutai Kartanegara sebagai desa budaya berdasarkan hasil survey dan keunikan budaya Suku Dayak Kenyah. Sehingga, pada tanggal 25 Juli Tahun 2007 Lung Anai ditetapkan sebagai desa definitif yang berdiri sendiri dengan Keputusan Bupati Kukar Nomor 180.188/HK-794/2007. Penetapan tersebut diharapkan mampu mendongkrak perkembangan ekonomi untuk kesejahteraan masyarakat dan menambah Pendapatan Asli Daerah (PAD) Kukar serta untuk melestarikan kebudayaan suku Dayak Kenyah Lepoq Jalan di Desa Lung Anai. Namun pada kenyataannya tujuan tersebut belum terealisasi dengan baik, hingga tahun ini Lung Anai belum menjadi destinasi unggulan di Kukar. Jika diperhatikan secara literatur, masih terdapat kesenjangan yang cukup jauh dengan desadesa budaya/wisata lainnya yang sudah berkembang bahkan mandiri di Kalimantan Timur. Penelitian ini bertujuan untuk menganalisis secara komprehensif potensi-potensi pariwisata Desa Lung Anai 
yang berbasis pada budaya dengan melakukan pendekatan community-based tourism (CBT) atau pariwisata berbasis masyarakat. Selain itu, penelitian ini juga diharapkan mampu memberikan rekomendasi teoretis dan teknis bagi Pemerintah Daerah Kabupaten Kutai Kartanegara dan stakeholder yang memiliki kepentingan bersama dalam mengembangkan Desa Budaya Lung Anai.

Copyright (C) 2019 Politeknik Negeri Samarinda. All rights reserved.

\section{Pendahuluan}

UNWTO lebih menekankan bahwa pariwisata sebagai sektor unggulan (leading sector) yang menjadi kunci dalam pembangunan wilayah dan peningkatan kesejahteraan masyarakat, karena pariwisata memiliki fungsi dan peran, yaitu: (1). Projob; (2). Pro-growth; (3). Pro-poor; dan (4). Pro-environment [UNWTO, 2005]. Keempat hal tersebut yang menginisiasi munculnya pariwisata berbasis masyarakat sebagai alternatif dalam mewujudkan pembangunan berkelanjutan dengan melibatkan masyarakat sebagai subjek yang aktif terhadap setiap aktivitas sekaligus mengontrol pengembangan pariwisata [Marinovski, 2018]. Pendekatan pariwisata berbasis masyarakat atau community based tourism (CBT) adalah sebuah konsep pengembangan destinasi pariwisata melalui pemberdayaan masyakat setempat dalam perencanaan, pengelolaan, dan penyampaian pendapat [Goodwin, 2009].

Desa wisata adalah salah satu representasi dari pembangunan pariwisata berbasis masyarakat yang difungsikan mampu mempercepat pertumbuhan ekonomi, sosial, budaya, dan lingkungan area pedesaan. Hasil survey atas kebudayaan Dayak Kenyah yang memiliki keunikan, Pada tahun 2005 Kampung Lung Anai ditetapkan oleh Bupati Kutai Kartanegara (Prof. Dr. Syaukani H.R., SE, MM.) sebagai desa budaya di bawah naungan program Pemerintah Daerah Kukar. Sehingga pada tahun 2007 tanggal 25 Juli, Lung Anai ditetapkan sebagai desa definitif yang berdiri sendiri dengan Keputusan Bupati Kukar Nomor 180.188/HK-794/2007 [Azis, 2017].

Sejauh ini, pemerintah dan stakeholder lain hanya menganggap kebudayaan itu sebatas tarian dan musik tradisional yang mereka mainkan, tanpa melihat korelasinya dengan lahan-lahan dan ritus perladangan masyarakat Suku Dayak Kenyah di Lung Anai. Kritik dan diskusi atas komodifikasi Desa Budaya Lung Anai menjadi topik yang seharusnya dianalisis secara komprehensif untuk menemukan benang merah antara program pemerintah dengan kesejahteraan masyarakat Suku Dayak Kenyah.

\section{Tinjauan Pustaka}

Penelitian ini menggunakan teori-teori dasar maupun terapan disertai dengan konsep-konsep definitif yang jelas sebagai alat analisis untuk memperoleh hasil penelitian yang objektif dan akuntabel dalam proses penggalian potensi-potensi desa di sektor pariwisata berbasis pada budaya yang dilakukan dengan pendekatan terhadap komunitas secara langsung.

\section{A. Pariwisata}

Naisbitt (1997) dan Hermantoro (2015) menjelaskan bahwa pariwisata adalah sebuah domain pembangunan dan bukan sektor pembangunan, karena sebuah domain berisi ruang dari berbagai dukungan kegiatan sektoral. Pariwisata terbangun atas sinegitas antara sektor dan outputnya sehingga menghasilkan output kolektif. Hermantoro (2017) menggambarkan untuk menghasilkan musik "Wonderful Indonesia", maka konduktor (Kemenpar) harus mampu mengarahkan dan menggerakkan partiturnya (rencana induk pariwisata) yang mudah dipahami oleh pemusik (sektoral/pelaku pariwisata) sesuai dengan keahlian dan tugasnya masing-masing [Hermantoro, 2017].

\section{B. Potensi dan Daya Tarik Wisata}

Potensi pariwisata (tourism resources) biasa disebut sebagai sumber daya pariwisata yang merupakan bibit unggul pariwisata yang belum dikelola dengan baik, sehingga belum dapat dikunjungi oleh wisatawan dalam 
jumlah yang signifikan. Potensi tersebut akan berubah menjadi daya tarik wisata (tourist attraction) ketika sudah dikelola dengan baik dan dapat dikunjungi oleh wisatawan dalam jumlah yang signifikan [Chalmer, 2011]. Sedangkan, daya tarik wisata dijelaskan secara singkat dalam UU No. 10 Tahun 2009, bahwa daya tarik wisata berbasis pada alam, budaya (berwujud dan tidak berwujud), dan buatan yang merupakan sebuah komponen destinasi yang dapat dibedakan dengan jenis komponen destinasi pariwisata lainnya seperti fasilitas umum dan fasilitas pariwisata, aksesibilitas, dan masyarakat [UU Nomor 10 / 2009].

\section{Desa Wisata}

Desa wisata adalah suatu bentuk integrasi antara atraksi, akomodasi dan fasilitas pendukung yang disajikan dalam suatu struktur kehidupan masyarakat yang menyatu dengan tata cara dan tradisi yang berlaku. Ini merupakan salah satu solusi yang ditempuh untuk meningkatkan kesejahteraan masyarakat desa adalah melalui pembangunan desa wisata [Nurjaya, 2011]. Desa wisata sebagai suatu produk wisata yang melibatkan anggota masyarakat desa dengan segala perangkat yang dimilikinya. Desa wisata tidak hanya berpengaruh pada ekonominya, tetapi juga sekaligus dapat melestarikan lingkungan alam dan sosial budaya masyarakat terutama berkaitan dengan nilai-nilai kebersamaan, kekeluargaan, dan gotongroyong. Dengan demikian, kelestarian alam dan sosial budaya masyarakat akan menjadi daya tarik bagi wisatawan yang melakukan perjalanan wisata [Sukmana, 2018].

\section{Budaya}

Potensi budaya adalah semua hasil cipta, rasa dan karsa manusia baik berupa adat istiadat, kerajinan tangan, kesenian, peninggalan bersejarah nenek moyang berupa bangunan, monumen, dan lain-lain. Potensi sosial budaya merupakan potensi yang terdapat di kehidupan masyarakat. Keberagaman budaya itu merupakan tantangan sekaligus peluang bagi masyarakat Indonesia. Setiap kelompok masyarakat (suku bangsa) di Indonesia pada hakekatnya mempunyai potensi-potensi sosial budaya yang kondusif dan dapat menunjang pembangunan. Potensi ini terkadang terlupakan begitu saja oleh kelompok masyarakat sehingga tidak dapat difungsionalisasikan untuk tujuan-tujuan tertentu. Tetapi banyak juga kelompok masyarakat yang menyadari akan potensipotensi sosial budaya yang dimilikinya, sehingga potensi-potensi tersebut dapat dimanfaatkan secara arif bagi keperluan kelompok masyarakat itu sendiri [Berutu, 2012].

\section{E. Community Based Tourism (Pariwisata Berbasis Masyarakat)}

Pariwisata berbasis masyarakat merupakan sebuah konsep pengembangan suatu destinasi wisata melalui pemberdayaan masyarakat lokal. Dimana masyarakat turut andil dalam perencanaan, pengelolaan, dan penyampaian pendapat. CBT harus memperhitungkan aspek keberlanjutan lingkungan, sosial, dan budaya karena dalam penerapannya difungsikan sebagai alat bagi pembangunan komunitas dan konservasi lingkungan atau dengan kata lain CBT merupakan alat bagi pembangunan pariwisata berkelanjutan. Masyarakat yang terlibat dalam aktivitas kepariwisataan dengan pendektana CBT memiliki kendali yang besar dalam keterlibatannya untuk mengembangkan dan mengelola kegiatan pariwisata yang mampu memberikan keuntungan ekonomi tidah hanya bagi masyarakat yang terlibat langsung, namun juga bermanfaat bagi masyarakat yang tidak terlibat secara langsung karena menimbulkan multplier effect atau efek pengganda [Murphy, 1995].

\section{Metodologi Penelitian}

\section{A. Teknik Pengumpulan Data}

Dalam penelitian ini, peneliti memilih beberapa metode pengumpulan data untuk mendapatkan data yang akurat dan kredibel, sehingga penelitian ini dapat dipertanggungjawabkan sebagai karya tulis ilmiah, yaitu:

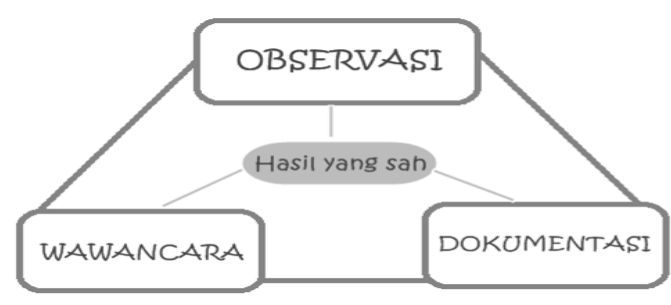


Gambar 1. Teknik Pengumpulan Data

\section{B. Teknik Analisis Data}

Peneliti menggunakan teknik analisis data secara kualitatif dengan model Miles and Huberman, yakni melalui data condensation, data display dan conclusion drawing/ verification [Miles, 2014]. Ketiganya harus saling berkaitan dan merupakan suatu siklus dan interaksi pada saat sebelum, selama, dan sesudah proses pengumpulan data dalam bentuk sejajar yang membangun wawasan umum yang disebut analisis [Silalahi, 2009]. Teknik analisis data model Miles dan Huberman digambarkan dengan pola seperti pada gambar di bawah ini :

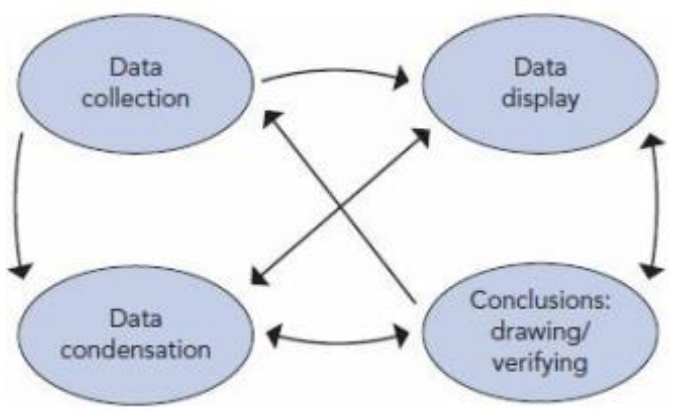

Gambar 2. Teknik Analisis Data Miles \& Huberman

\section{Hasil dan Diskusi}

Secara geografis, Desa Lung Anai adalah salah satu wilayah yang terletak di pinggiran Sungai Jembayan (anak sungai Mahakam) dengan pola pemukiman yang tidak lagi mengikuti pola ruang seperti kampungkampung di sebelahnya yang membentang mengikuti alur sungai. Pemukiman orang kenyah ini justru membentuk pola huruf $\mathrm{T}$ dengan tidak mengikuti alur sungai. Masyarakat Lung Anai juga tidak lagi memiliki rakit jambang di sungai karena aktivitas berladang saat ini dapat ditempuh dengan jalur darat (kendaraan bermotor). Aktifitas mandi dan mencuci pun tidak lagi dilakukan di sungai sejak air dari pegunungan dapat dialirkan ke penampungan desa dan kemudian setelah disaring dapat dialirkan ke rumah masing-masing warga sejak tahun 1994.

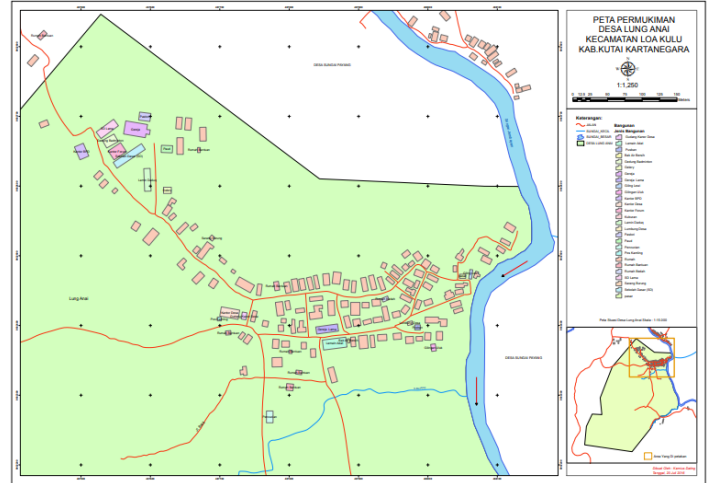

Gambar 3. Peta Pemukiman Desa Lung Anai

A. Identifikasi Desa Wisata Berbasis Budaya dengan Konsep 4A+1C

1. Attraction (Atraksi / Daya Tarik Wisata)

\section{a. Alam}

- Air Terjun Uung (yang secara geografis masuk wilayah Desa Sungai Payang) dapat dimanfaatkan untuk menjadi salah satu daya tarik alam dengan cara bekerjasama dan koordinasi atau bagi hasil dengan Desa Sungai Payang.

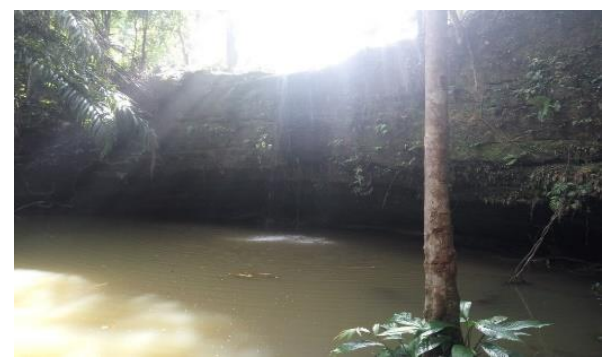

Gambar 4. Air Terjun Uung

- Aktivitas memancing dan menjala Ikan di Parit dengan atau tanpa perahu. Umpan pancing dibuat dengan buah Saleng.

- Wisata air "Susur Sungai Jembayan" dengan Perahu Dayung dan Ketinting (Cas), atraksi ini adalah program 5 desa yang terhubung oleh Sungai Jembayan, yaitu Desa Jembayan Dalam, Jembayan Tengah, Jembayan Luar (Induk), Sungai Payang, dan termasuk Lung Anai. 


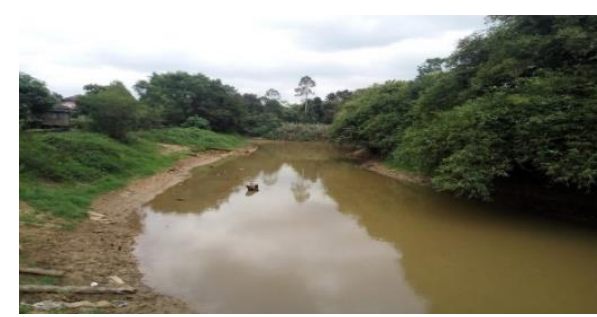

Gambar 5. Sungai Jembayan

- Pengenalan Tanaman Medis (Budidaya Akar Klawit/Bajakah dan Akar Ulin untuk diminum airnya sebagai obat Kanker) sebagai aktivitas wisata alam berbasis pendidikan, akar Klawit dan Akar Ulin kering bisa dijadikan buah tangan bagi wisatawan setelah dikemas dengan baik dan menarik.

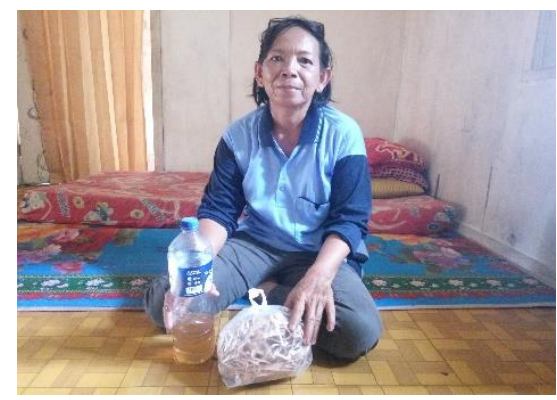

Gambar 6. Akar Kelawit Kering dan Air Rebusannya

- Tradisi Berladang bisa dijadikan daya tarik agrowisata sebagai minat khusus yang akan dijelaskan secara khsusus pada bagian wisata minat khsusus di bawah.

\section{b. Budaya}

- Kesenian Tradisional (Tarian Datun Julud (tari massal), Hudoq (tari topeng), Kancet Lasan (tari tunggal), Tari Perang, dan bermain musik sampeq dan jatun utan atau kelintangan) yang secara khusus diadakan setiap hari Sabtu/Minggu, jika memungkinkan dibuat sebuah drama musikal yang menceritakan folklore atau cerita rakyat khas Lepoq Jalan seperti yang ada di buku dari Yayasan Desantara dan Naladwipa.

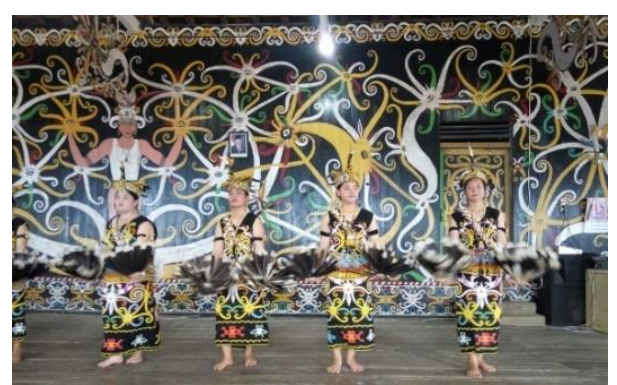

Gambar 7. Tarian Khas Dayak Kenyah Lepoq Jalan

- Nyanyian khas Dayak Kenyah Lepoq Jalan bisa diciptakan atau memakai lagu yang sudah ada, biasanya lagulagu khas Dayak Kenyah Lepoq Jalan dinyanyikan ketika acara Mubes Pekenoq Tawai yang diadakan setiap tahun.

- Acara Mubes Suku Dayak Kenyah Lepoq Jalan (Pekenoq Tawai) yang biasa diadakan setiap satu tahun sekali dengan tempat yang berpindah-pindah sesuai dengan tempat domisili masyarakat Lepoq Jalan pasca migrasi.

- Pesta Panen dan Panen Raya Padi (Uman Ubeq dan Uman Undrat) yang diadakan sekitar bulan Februari dan Mei setiap tahunnya.

- Memperlihatkan Budaya Gotong Royong, Kekompakkan dan Kebersamaan yang kuat masyarakat Dayak Kenyah Lepoq Jalan dari berbagai kalangan (diadopsi dari hukum adat) misalnya ada selingan gerakan kebersihan setelah acara kesenian berlangsung.

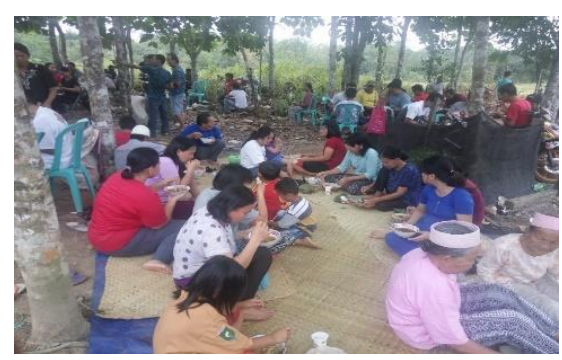

Gambar 8. Kekompakkan Masyarakat Lung Anai

- Memperkenalkan Budaya Keamanan yang unik, misalnya Motor yang selalu diparkir di luar rumah, Kunci Motor dan Rumah yang selalu menggantung tanpa takut kehilangan. 


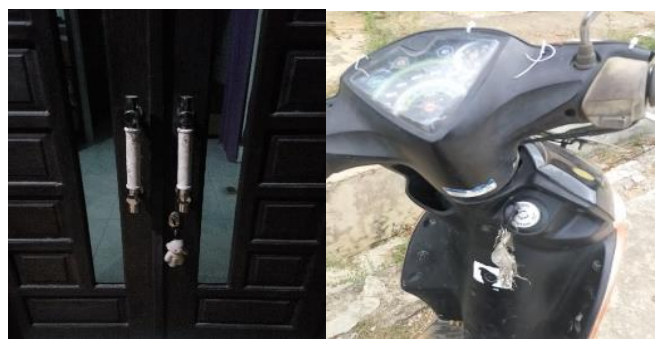

Gambar 9. Kunci \& Rumah yang selalu Menggantung

- Memperkenalkan bahasa Dayak Kenyah Lepoq Jalan dengan kamus mini dan praktek percakapan secara langsung dengan masyarakat.

\section{c. Buatan dan Kreatifitas}

- Ukiran-Ukiran khas Suku Dayak Kenyah Lepoq Jalan (motifnya: Kalung Asu, Kalung Udang, Kalung Kembang Guci/Tajau dan Macan, Kalung Pamen untuk Pintu Lamin, Kalung Besulan untuk list dinding bawah \& atas Lamin, Kalung Tapeh untuk Dinding Lamin, Bang-Bang Pang (Lukisan orang sebagai Komando), Kalung Udoq hanya gambar kepala. Ukiran-ukiran tersebut terpampang dengan jelas pada dindingdinding Lamin Adat dan Lamin Daduq dengan ukuran yang beragam dihiasi dengan warna-warni yang menarik untuk dijadikan sebagai spot berfoto bagi pengunjung. Macam-macam ukiran dan contohnya motifnya dapat dilihat pada gambar di bawah ini.

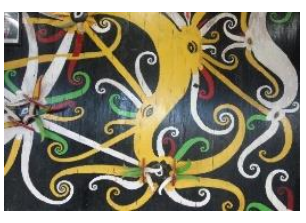

Kalung Asu \& Udang

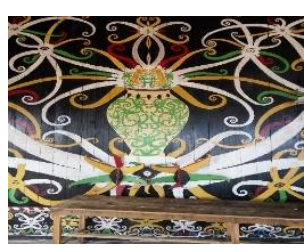

Kalung Guci/Tajau \& Macan

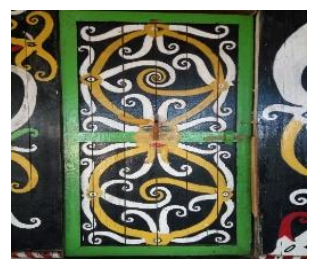

Kalung Pamen/Pintu

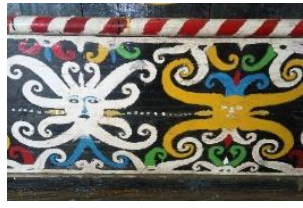

Kalung Udoq/Besulan

Bang-Bang Pang

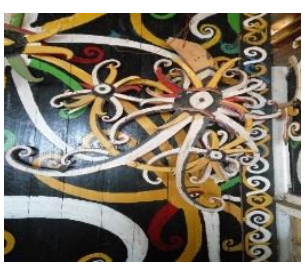

Ujon / Ujon Alut

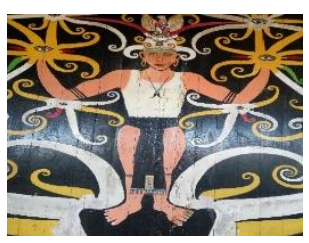

Gambar 10. Ukiran-ukiran (Kalung) Khas Dayak Kenyah Lepoq Jalan

- Ukiran Ujon dan Ujon Alut sebagai ukiran atap rumah.

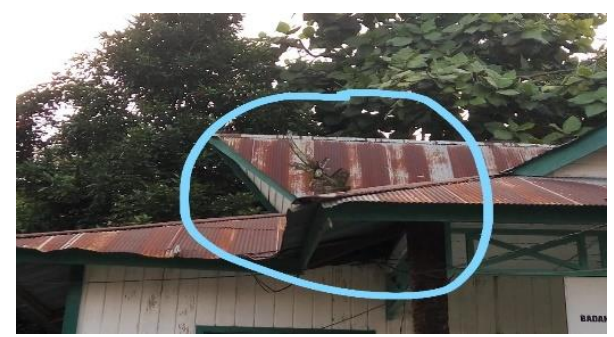

Gambar 11. Contoh Ukiran Ujon di Kantor BPD Lung Anai

- Patung-Patung khas Dayak Kenyah Lepoq Jalan yang akan dilengkapi dengan kran air

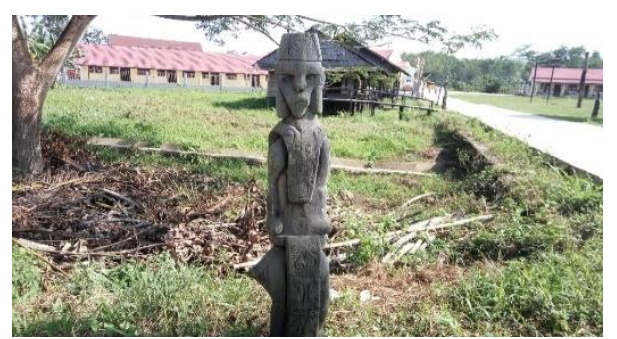

Gambar 12. Patung Khas Dayak Kenyah Lepoq Jalan

- Bangunan Lumbung Pangan Desa yang unik

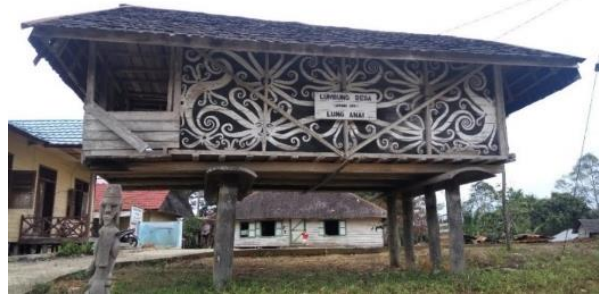

Gambar 13. Lumbung Pangan

- Bangunan Lamin Adat \& Daduq (bisa dimanfaatkan sebagai homestay)

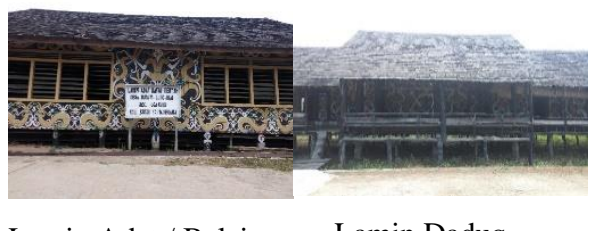

Lamin Adat / Balai Lamin Daduq

Gambar 14. Lamin Adat \& Lamin Daduq

- Kerajinan Tangan dari Rotan dan Manik-manik serta Kaos bertuliskan Lung Anai dapat dibuatkan stand bagi masyarakat yang mau menjualnya, kerajinan ini dapat juga dibuat sebagai 
welcoming souvenir yang diberikan secara gratis kepada wisatawan yang datang dan sudah memiliki tiket masuk, contohnya gelang dan kalung sederhana dari manik-manik. Selain itu, dapat pula dikembangkan atraksi wisatawan membuat kerajinan tangan dari rotan dan manik-manik. Kaos dengan motif Dayak dan tulisan Lung Anai dapat dijadikan merchandise yang dapat dijual kepada wisatawan.

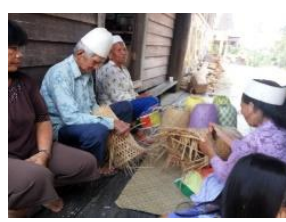

Kerajinan Tangan dari Rotan
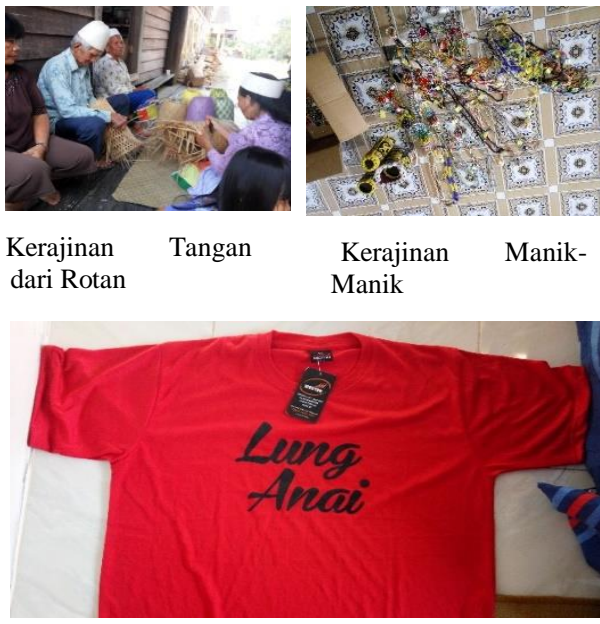

Kerajinan ManikManik
Kaos Khas Lung Anai

Gambar 15. Kerajinan Tangan \& Souvenir Lung Anai

- Makanan Khas Suku Dayak Kenyah Lepoq Jalan yang bisa dijadikan makanan pembuka atau welcoming food (Caktung Ubi, Pito, Anyeuco, Lemang, Undrat, Jenai, Borak, Jampau, Napu, dan Tupyiu Macan) dan bisa juga dibuatkan stand untuk dijual kepada wisatawan.

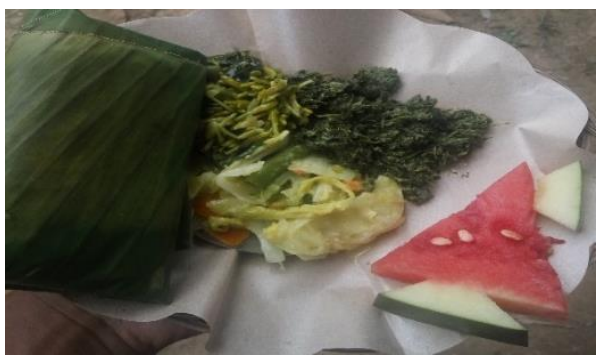

Caktung Ubi \& Tupyiu Macan

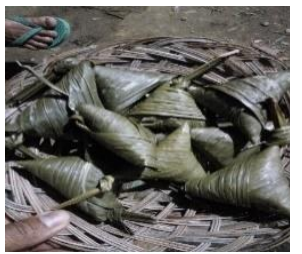

Pito

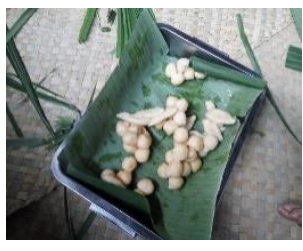

Anyeuco
Gambar 16. Makanan Khas Dayak Kenyah Lepoq Jalan Lung Anai

- Kampung Kakao untuk Makanan Olahan Kakao, jika memungkinkan dibuatkan sebuah lahan khusus untuk kampung Kakao ini disertai dengan Atraksi Pemanfaatan Limbah Pulp dan Kulit Kakao.

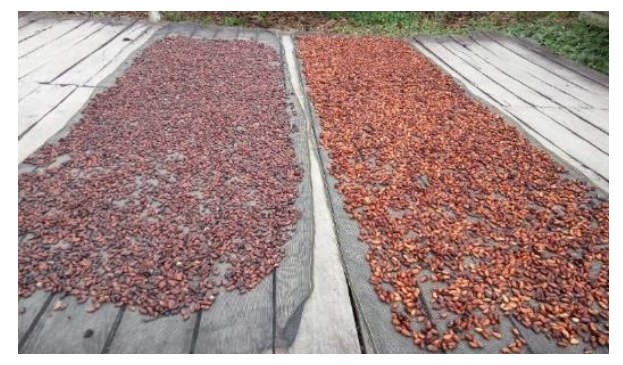

Gambar 17. Biji Kakao yang sedang dijemur

- Atraksi berburu sinyal (disediakan wifi di Lamin) dibuka ketika malam hari untuk wisatawan yang menginap sambil berburu sinyal ditemani dengan atraksi memposting kegiatan di malam hari melalui medsos.

- Kampung Babi dibuatkan atraksi memberi makan Babi oleh wisatawan, jika memungkinkan dibuatkan sebuah lahan khusus yang terpisah dengan pemukiman agar kebersihan tetap terjaga dengan baik.

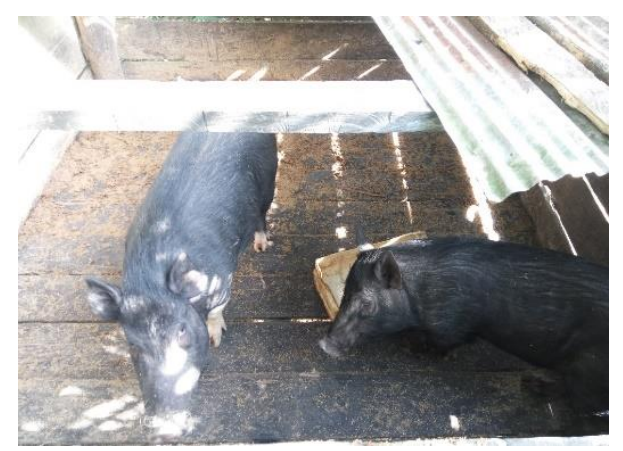

Gambar 18. Salah Satu Ternak Babi yang Dimiliki Masyarakat

- Permaianan Tradisional (Sumpit, Gasing dengan kulit kayu Kemaran, Tombak, Huling, dll) mengajak wisatawan untuk bersama-sama memainkan permainan-permainan tradisional masyarakat Kenyah Lepoq Jalan.

- Photo dan Selfie Boot dengan Baju Adat, Bacdrop dan tulisan-tulisan yang menarik wisatawan disertai dengan lomba foto dan postingan positif- 
kreatif yang diupload di medsos (instagram) dengan hastag \#desabudayalunganai yang dilakukan selama kegiatan berlangsung dan disiapkan hadiah sederhana untuk beberapa orang pemenang.

\section{d. Agro-Wisata sebagai Atraksi Minat} Khusus

Paket Wisata ini diisi dengan kegiatan berladang (bertani dan berkebun, seperti panen Kakao, Karet, Durian, Sawit, dan Padi Gunung) khas Suku Dayak Kenyah Lepoq Jalan, yang diperuntukkan bagi wisatawan yang menginap minimal 1 malam, mereka dapat menginap di Kubuq (Rumah Ladang) yang disediakan oleh Petani atau Pekebun. Khususnya Komoditas Kakao yang menjadi primadona masyarakat Lung Anai, karena hampir 90\% masyarakat menanam Kakao dengan jumlah yang bervariatif setiap orangnya.

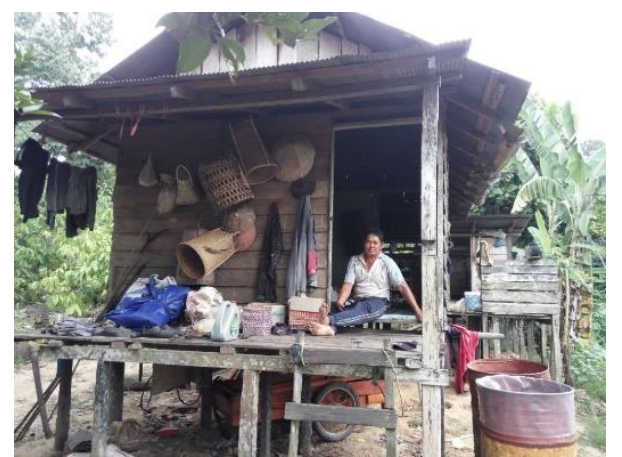

Gambar 19. Kubuq atau Rumah Ladang Suku Dayak Kenyah Lepoq Jalan

\section{Amenities (Fasilitas Pendukung)}

a. Transportasi

Jalur Darat dapat ditempuh dengan kendaraan bermotor (Sepeda Motor dan Mobil), akan tetapi bermasalah bagi wisatawan jauh yang tidak ada kendaraan karena belum ada angkutan umum, sehingga mereka harus sewa kendaraan yang pasti biayanya akan lebih besar dibandingkan jika ada kendaraan sendiri dan ada angkutan umum.

\section{b. Akomodasi (Homestay)}

Penyediaan homestay dapat dilakukan di rumah-rumah warga yang mau disewakan dan menambah penghasilan atau dapat juga dilakukan di Lamin
Daduq, bentuk akomodasi ini jika memungkinkan dilengkapi dengan kebutuhan makan dan minum wisatawan.

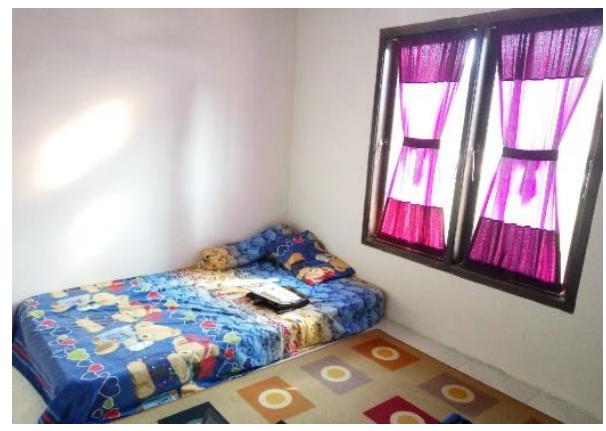

Gambar 20. Homestay Mama Naya Milik Warga

c. Rumah Makan

Bisa disediakan lahan khusus untuk warga yang mau menyediakan makanan dan minuman bagi wisatawan baik yang berupa makanan cepat saji maupun yang dimasak secara manual atau menyediakan makanan khas daerahnya, serta dapat juga bekerjasama dengan para pemilik homestay, atau dibuat satu area dengan Kampung Kakao sehingga tidak hanya makanan olahan Kakao yang disajikan, tetapi juga makanan lainnya.

\section{d. Tempat Ibadah}

Jika memungkinakn dan ada ijin dari Pemdes, Lembaga Adat, dan Pengurus Gereja bisa dibangunkan sebuah Musholla kecil di Lamin Adat/Daduq untuk mengantisipasi banyaknya wisatawan muslim.

\section{e. Toilet Umum}

Disediakan di Lamin Adat, Lamin Daduq, Kubuq dan rumah-rumah warga yang dijadikan homestay.

\section{f. Laundry}

Bagian ini dapat dikoordinasikan dengan pemilik homestay masing-masing warga atau melalui pilihan paket wisata yang dipilih wisatawan

\section{g. Bank Sampah Masyarakat}

Program pendukung sebagai alternatif untuk menjaga kebersihan Desa Budaya Lung Anai

h. Peralatan Kebakaran Sederhana

Diperlukan untuk mengantisipasi kebakaran yang terjadi, karena 
kebanyakan rumah di Lung Anai adalah rumah panggung yang berbahan kayu, sehingga mudah terbakar apalagi ketika musim kemarau.

\section{i. Bank, ATM, dan Money Changer}

Masih terbatas karena jauhnya lokasi dengan pusat ibukota kecamatan Loa Kulu.

\section{Accessibility (Sarana-Prasarana)}

a. Jalan untuk jalur darat dari Kecamatan Loa Kulu sekitar $25 \mathrm{~km}$, atau bisa lewat Margasari tetapi jalan masih kecil meskipun lebih dekat. Dari Samarinda dapat ditempuh dengan durasi perjalanan sekitar 2 jam. Kondisi jalan masih kurang baik, apalagi jalanan akan sangat berdebu ketika panas terik, dan menjadi lumpur ketika hujan turun.

b. Akses Telekomunikasi dan Internet yang tersedia dari provider Telkomsel (4G).

\section{Ancillaries (Layanan Tambahan)}

a. Kelompok Sadar Wisata (Pokdarwis) Lung Anai

Setelah melakukan wawancara dengan beberapa informan, lembaga ini masih belum berjalan dengan efektif dan maksimal, dikarenakan belum adanya dukungan kuat dari Pemerintahan Desa Lung Anai. Akan tetapi pada tanggal 8 September 2019 Ketua Pokdarwis (Bapak Sidaris, S.Pd.) beserta jajarannya berkomitmen akan mengaktifkan kembali kelompok ini jika terus didampingi secara akademik dari peneliti dan bantuan materil tentunya dari pihak swasta.

\section{b. Lembaga Adat Desa}

Selama ini, lembaga inilah yang berperan aktif dalam setiap acara-acara budaya yang dilaksanakan di Lung Anai. Lembaga ini dikepalai oleh Bapak Ruben Bilung, beliau berkomitmen untuk membantu mensukseskan Desa Budaya Lung Anai.

\section{c. Pemerintah Desa}

Belum ada arah pembangunan yang jelas dari Pemdes mengenai keberlanjutan desa budaya termasuk dukungan- dukungan lainnya. Memang Pemdes sepakat untuk mengarahkan pembangunan Desa Lung Anai sebagai Desa Budaya, akan tetapi belum ada strategi untuk menggapai tujuan tersebut yang dikarenakan minimnya pengetahuan tentang Desa Wisata berbasis Budaya. Jadi setelah desa ini ditetapkan sebagai desa budaya Pemdes yang saat ini dipimpin oleh PJ Kades yaitu Bapak Gun, bingung apa langkah selanjutnya yang harus diambil karena tidak ada bimbingan secara intensif dari Pemkab Kukar khususnya Dinas Pariwisata Kukar untuk membina SDM Lung Anai.

\section{d. Group Kesenian "Tiking Leka” Lung} Anai

Kelompok kesenian ini dipimpin oleh Bapak Bit Sianto, yang membina dari awal segala hal yang berkaitan dengan kesenian tradisional (tari dan musik) khususnya melatih generasi muda untuk bisa memainkan seni tradisional Dayak Kenyah Lepoq Jalan agar tidak hilang karena arus modernisasi yang begitu kuat.

e. Puskesmas Pembantu (Pusban)

Difungsikan sebagai tempat untuk memberikan pertolongan pertama jika terjadi kecelakaan atau sakit bagi wisatawan dan masyarakat setempat.

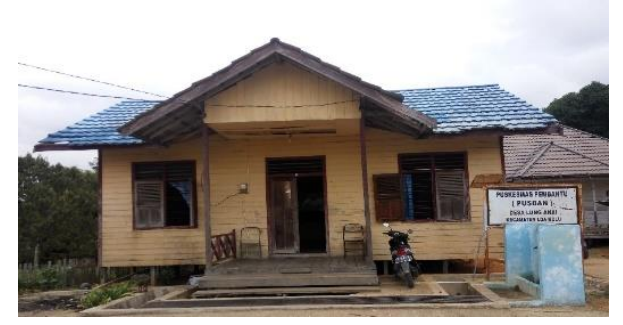

Gambar 21. Puskesmas Pembantu Desa Lung Anai

\section{Community}

Involvement (Keterlibatan Masyarakat)

a. Partisipasi Aktif Masyarakat setiap Kalangan (Anak-anak, Remaja, Dewasa, Orang Tua)

Dapat dilihat dari tingginya antusiasme masyarakat dari berbagai kalangan untuk berpartisipasi dalam setiap kegiatan yang berkaitan dengan kebudayaan Suku Dayak Kenyah Lepoq Jalan. Partisipasi aktif ini lahir dari kebiasaan-kebiasaan yang diwariskan dari nenek moyang mereka untuk menanamkan rasa tangung 
jawab sebagai satu keluarga Dayak Kenyah Lepoq Jalan.

\section{b. Nilai-nilai Kebersamaan dan Gotong} Royong

Nilai-nilai ini begitu kuat dirasakan ketika ada kegiatan-kegiatan yang berkaitan dengan tradisi-tradisi masyarakat seperti acara keluarga, tunangan, lamaran, nikahan, bersih-bersih lingkungan, hari besar nasional, natal, kematian, dan lain-lain. Peneliti dapat memprediksi dengan kuatnya nilai-nilai di atas pada masyarakat Lung Anai dan jika pengembangan desa budaya ini terus dilakukan secara berkelanjutan, maka masyarakat Lung Anai akan memberikan komtribusi yang signifikan dalam pengembangan Desa Wisata berbasis budaya yang maju bahkan mandiri di masa depan.

Dengan demikian, berdasarkan hasil observasi terhadap segala potensi yang dimiliki oleh Lung Anai ditinjau dari atraksi/daya tarik wisata, fasilitas penunjang, sarana pra-sarana, layanan tambahan dan keterlibatan masyarakatnya dapat ditarik asumsi bahwa karakteristik unik Lung Anai berpotensi dapat menarik dan mendatangkan pengunjung, dengan adanya aktivitas yang terintegrasi dan terkoneksi satu sama lain dalam rangkaian "Produk Agro Wisata Kakao dan Klawit Kesenian Tradisional - Atraksi Berladang - Live in Masyarakat - Produk Kerajinan". Rangkaian tersebut dapat dikemas menjadi sebuah brand image pariwisata Lung Anai secara holistik, yaitu Paket Wisata Agro-Budaya Lung Anai.

\section{Kesimpulan}

Penetapan Lung Anai sebagai desa definitif dengan gelar desa budaya bukan tanpa alasan, memang setelah dilakukan observasi dikuatkan dengan wawancara langsung, Lung Anai memiliki potensi yang besar untuk dapat dikembangkan menjadi desa wisata berbasis budaya yang maju bahkan mandiri. Jika dilihat dari hasil analisis $4 \mathrm{~A}+1 \mathrm{C}$, kekurangan Lung Anai terletak pada amenities (fasilitas pendukung), accessibility (sarana), dan ancillaries (layanan tambahan), kelebihan Lung Anai yang paling kuat terletak pada Daya Tarik Wisatanya baik berupa alam, budaya, maupun buatan ditambah dengan community involvement yang dilandasi dengan nilai-nilai gotong royong dan kerja sama. Selain itu, ada beberapa faktor-faktor yang menjadi hambatan secara internal maupun eksternal, yang pada intinya bermuara pada sikap apatis Pemkab Kukar khususnya Dinas Pariwisata setelah menetapkan Lung Anai sebagai desa budaya tanpa pendampingan intensif. Sehingga, berimplikasi pada minimnya pengetahuan dan pemahaman masyarakat terhadap teknik pengelolaan desa budaya secara holistik.

\section{References}

[1] UNWTO - United Nations World Tourism Organization. 2005. Making Tourism More Sustainable: A Guide for Policy Makers; UNWTO: Madrid, Spain.

[2] Marinovski, C. 2018. Community Development Approach to Community Based Tourism: The Case of Beni Na'im in Palestine. University of Helsinki.

[3] Goodwin, H., \& Santilli, R. 2009. Community Based Tourism: a Success?. ICRT Occasional Paper 1.

[4] Azis, A. 2017. Kontestasi Identitas Dayak di Lung Anai: Potret Pergulatan Agama, Pariwisata, dan Ruang Hidup. Yogyakarta: Universitas Gadjah Mada Press.

[5] Hermantoro, H. 2017. Memahami Konsep Dasar Pariwisata. Depok: Aditri.

[6] Chalmer, W. D. 2011. The Origin of The Species Homo Touristicus: The Evolution of Travel froom Greek Spas to Space Tourism. Bloomington: iUniverse, Inc.

[7] Undang-undang Republik Indonesia Nomor 10 Tahun 2009 tentang Kepariwisataan.

[8] Nurjaya, I. W. 2011. "Persepsi Wisatawan Mancanegara Terhadap Potensi Pariwisata di Kelurahan Desa adat Ubud, Kabupaten Gianyar". Tesis, Pasca Sarjana: Universitas Udayana.

[9] Sukmana, E. 2018. Analisis Pengaruh Partisipasi Masyarakat, Peran Pemerintah Desa, Jumlah Kunjungan Wisatawan, Dan Pendapatan Desa Dari Pengelolaan Desa Wisata Terhadap Kesejahteraan Masyarakat Di Desa Wisata Cibuntu Dan Citundun. Tesis. Jakarta: STP Trisakti. 
[10] Berutu, Lister. 2012. Mengenal Upacara Adat Pada Masyarakat Pakpak. Medan: Grasindo Monoratama.

[11] Murphy, P.E. 1995. Community Driven Tourism Planning. New York: Penguin Books.
[12] Miles, M. B. \& Huberman, A. M. 2014. Qualitative Data Analysis: A Sourcebook of New Methods, SAGE: Beverly Hills.

[13] Silalahi, U. 2009. Metode Penelitian Sosial. Bandung: Refika Aditama. 